\title{
PREVALENCE OF COMORBIDITIES IN SOCIALLY ASSISTED PATIENTS IN THE SANODENTAPRIM PROGRAMME
}

Cite this article IleaA, Buhatel D, Moga M, Feurdean C, Ionel A, Sava A, Lucaciu 0, Sarbu A, Campian RS. Comorbities prevalence in socially assisted patients in the sanodentaprim programme. Stoma Edu J. 2014; 1(1):59-64

https://doi.org/10.25241/stomaeduj.2014.1(1).art.10

\section{Abstract}

Introduction: Once with the growth of the population's life expectancy in the world but also in Romania, the patients in dental offices often suffer from associated diseases for which they are under constant medication.

The objectives of the study were to evaluate the prevalence of the associated diseases and of constant medication for a group of socially assisted patients.

Methods: The study included a total of 1176 socially assisted patients from the

SANODENTAPRIM program who were seen during the period from April 15, 2010 to

December 1, 2010. The observation files, medical notes and certificates from the general practitioner or from the attending specialist physician were studied.

Results: The patients from the studied group presented a prevalence of comorbidities of $92 \%$. The most frequent associated diseases were cardiovascular (36\%). A percentage of $84 \%$ of the studied patients were under constant medication.

Conclusion: The risks of the patient with general disease have to be evaluated according to a detailed anamnesis corroborated with paraclinical examinations and, if needed, in collaboration with the attending doctor. The adverse effects of constant medication need a special attention, especially when certain classes of drugs interfere with dental treatments. Keywords: associate diseases, medication, prevalence, socially assisted

\section{Aranka llea** Dan Buhățel'b, Minodora Mogab, Claudia Feurdean ${ }^{b}$, Anca Ionel' Arin Savab, Ondine Lucaciuc, Adina Sârbub, Radu Septimiu Câmpiand}

Oral Rehabilitation Department, Oral Health and Management of the Dental Office Department, Faculty of Dentistry, "Iuliu Hațieganu" University of Medicine and Pharmacy, Cluj-Napoca, Romania a. MD, DMD, Assistant Professor b. DMD, Assistant Professor c. DMD, Lecturer

d. DMD, MD, Professor, Head of Oral Rehabilitation Department, Dean of Faculty of Dentistry

\section{Introduction}

The relationship between general diseases and the pathology of the stomatognathic system is multiple and bidirectional. The oral health has consequences upon the general health and the correlation between the dental foci and the cardiovascular diseases or, recently, between the parodontal disease and cardiovascular disease, is well known (1). The gravity of the parodontal disease together with the high value of the reactive $C$ protein with high sensitivity (hPCR) could be predictive for the imminence of installation of an acute cardiovascular incident (2). Also, general diseases have an echo upon the oral health. General conditions could have oral manifestations and could influence the evolution, the manifestations and the responses to the therapy instituted in the oro-maxillo-facial diseases. In the study realized by Anders Holmlund, Gunnar Holm and Lars Lind it is shown that life expectancy is related to the number of teeth on the dental arcades: the mortality due to cardiovascular disease is higher in patients with less than 10 dental units remaining (3).

Knowing the general diseases of the patient is also crucial for the dentist. The decision of the opportunity, of the time of intervention, the specific preparation and the type of applied treatment depends on the presence or lack of associated diseases, on the degree of metabolic and functional compensation or on the patient's hemodynamic balance. In this sense it is important to evaluate the prevalence of the associated diseases for the patients who are accessing the services of dental medicine. These data are very important especially if we correlate this information with social aspects.

SANODENTAPRIM is a program for socially disadvantaged patients (retired with incomes below $1000 \mathrm{RON}$, retired due to illness, the unemployed, patients with disabilities and people with varying degrees of disability that require a registered nurse) and runs through the partnership between the Town Hall of Cluj-Napoca and the Faculty of Dentistry of the University of Medicine and Pharmacy, Cluj-Napoca. Under this program, patients benefit from free dental care.

Received: 17 November 2013 Accepted: 16 December 2013

*Corresponding author:

Assistant Professor llea Aranka, MD, DMD

Oral Rehabilitation, Oral Health and Management of Dental Office Department, Faculty of Dentistry, "Iuliu Hațieganu" University of

Medicine and Pharmacy,

Cluj-Napoca, Romania.

8, Victor Babeş st., RO-400012,

Cluj-Napoca, Romania.

Tel: 0746151210,

Fax: 0040-0264596291.

e-mail: cseh.aranka@umfluj.ro 
Considering that the data concerning the prevalence of the general diseases in Romania is scarce and incomplete, the authorsproposed to evaluatethisaspect for a group of socially assisted patients who accessed the SANODENTAPRIM program. The prevalence represents the frequency of the disease cases (new and old) existing in a defined population at a certain moment - the actual prevalence - or during a certain period - the periodic prevalence. The prevalence is a specific indicator of the study of morbidity by chronic diseases. In the case of prevalence, the observation unit is the new and old cases of disease.

The need for oral rehabilitation is different from one patient to another and it is determined by the gravity of the dental/parodontal diseases and the diseases from the oro-maxillo-facial area. The socially assisted patient has a low revenue and this is the reason why they are accessing the dental medicine services in the private system in a small proportion or even not at all. The social insurance system in Romania concerning dental medicine has a low budget, each insured patient having the amount of about $3 \mathrm{RON}$ peryear. This social program offers the possibility for these social disadvantaged groups to access free dental medicine services. The primary prevention and the early interception of these diseases of the stomatognathic system may reduce the need of complex oral rehabilitation.
The objectives of the study were:

1. Assessing the prevalence of comorbidities in socially disadvantaged patients who accessed the SANODENTAPRIM program between April 15, 2010 and December 1, 2010.

2. Evaluate the types and classes of constant medicines used by these patients.

\section{Methods}

The retrospective study of the prevalence of associate diseases was made upon a number of 1176 patients having accessed the SANODENTAPRIM program during the period of April 15, 2010 - December 1 , 2010. Observation files, the medical notes and certificates from the general practitioner or from the attending physician have been studied. These files were completed after the patient history, clinical and paraclinical examinations of the patients by the dentists, specialist doctors or students during their classes in the Oral Rehabilitation Department.

\section{Results}

From the group of 1176 patients, the women accounted for $59 \%$ as can be seen in Fig. 1. The age histogram shows that the majority of patients had ages between 60 and 65 years as can be noticed in Fig. 2 . The actual prevalence of the associated diseases in the

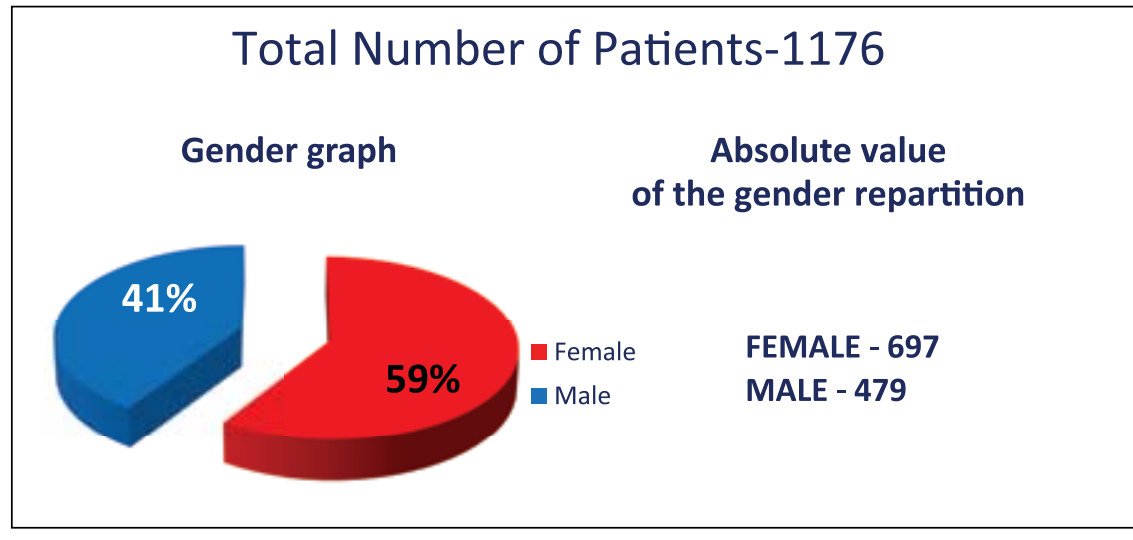

Figure 1.

Gender distribution

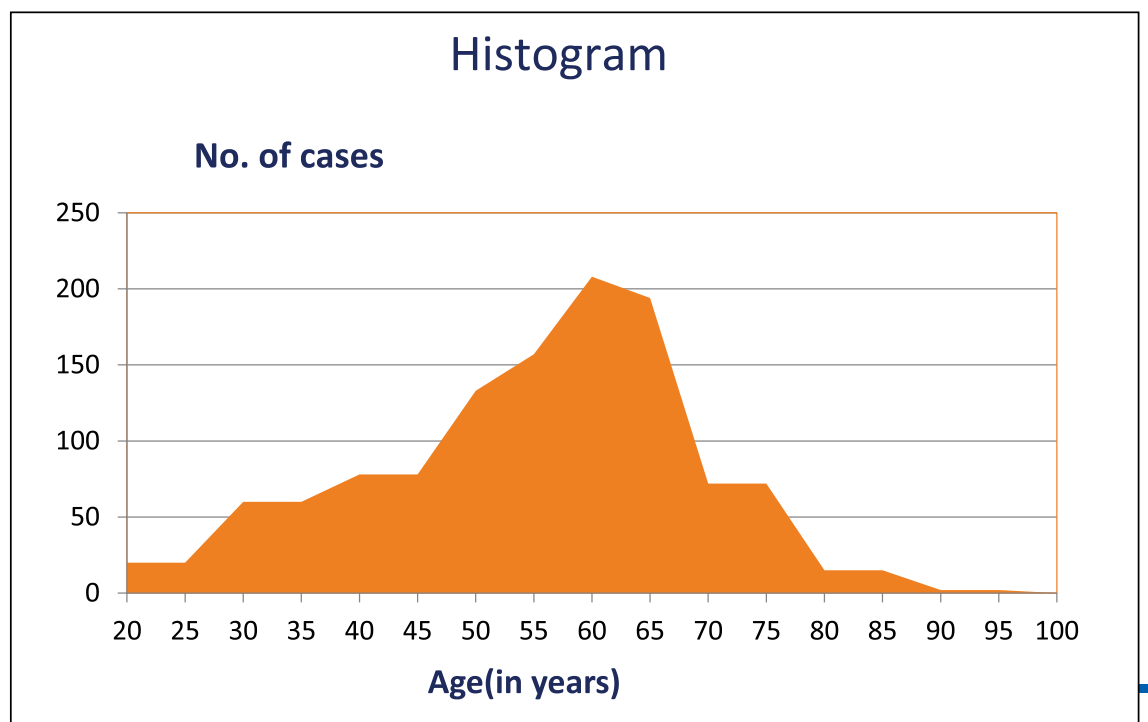

Figure 2.

Distribution of the study group by age 


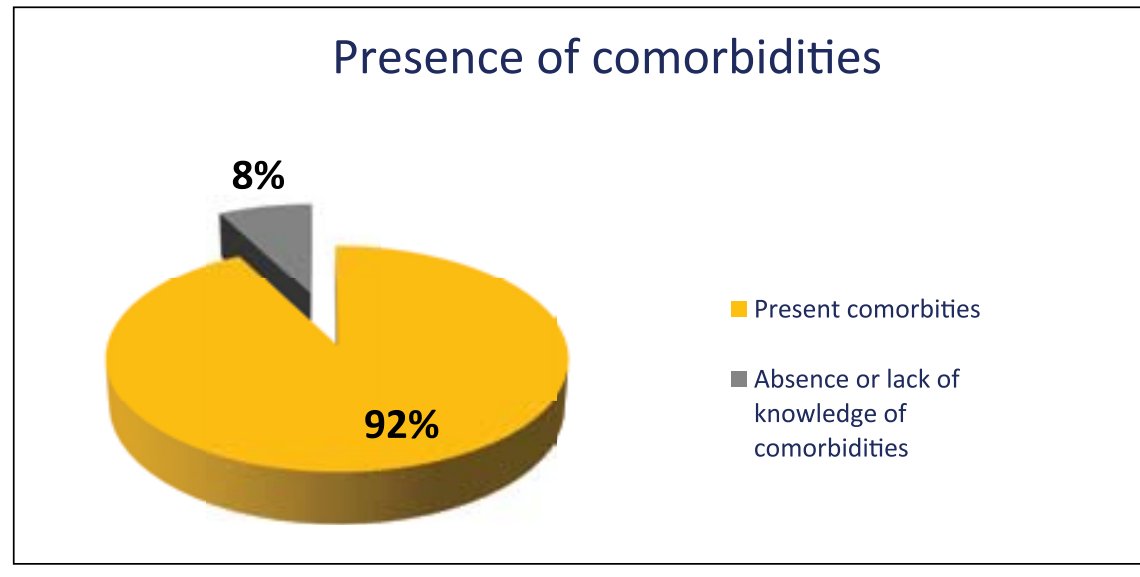

Figure 3.

Presence of comorbidities

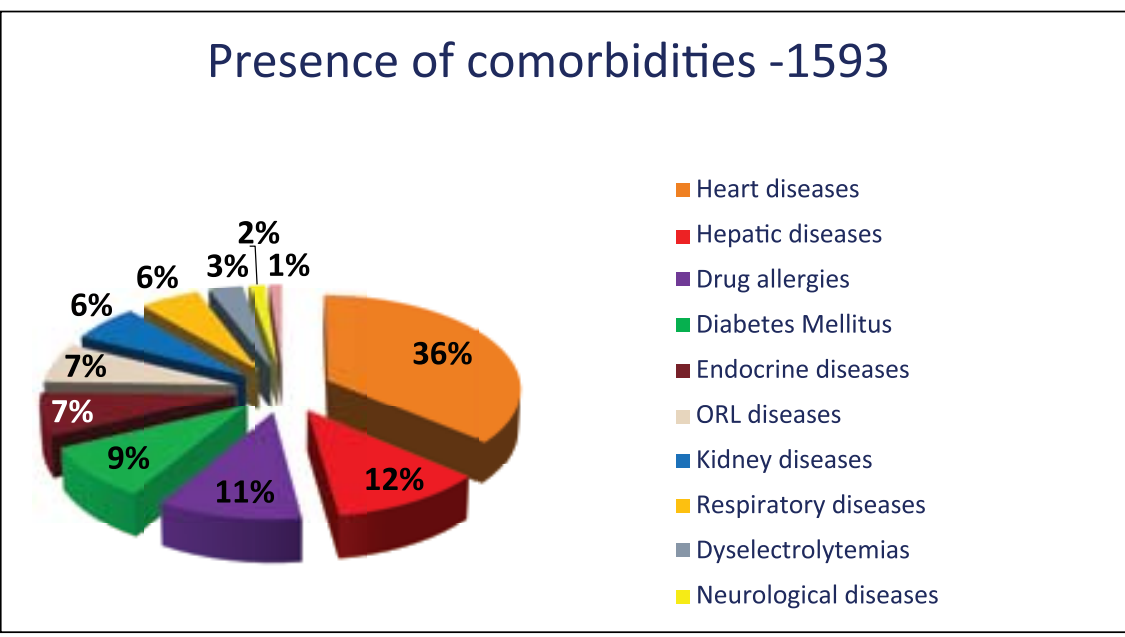

Figure 4.

Actual comorbidities

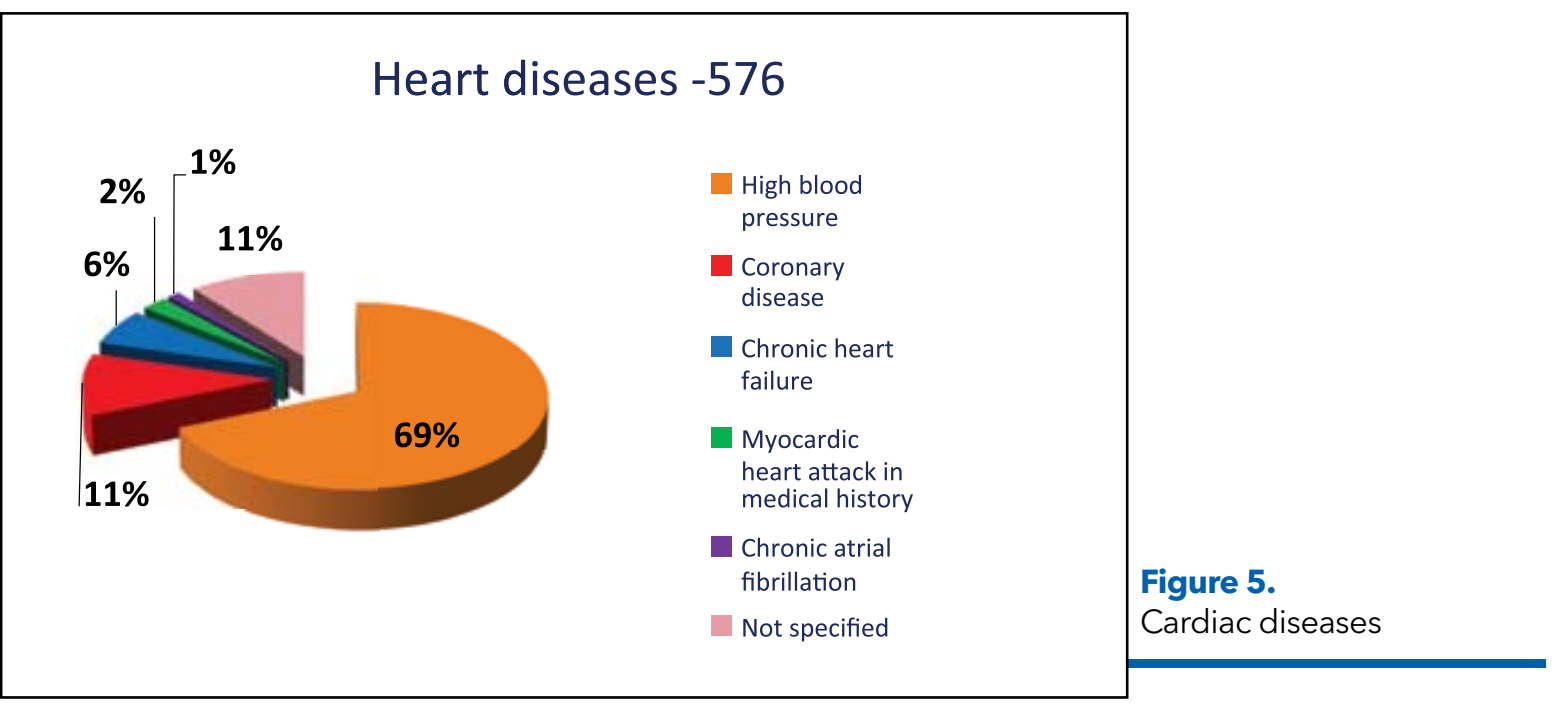

study group was high and accounted for $92 \%$ as shown in Fig. 3. The specific prevalence on different types of affections is represented in Fig. 4. The most frequent comorbidities were those of the cardiovascular system $(36 \%)$, some of the patients presenting two or more associated diseases. Cardiovascular diseases were followed by liver diseases with a prevalence of $12 \%$.

From the cardiovascular diseases, the most prevalent was high blood pressure (HBP) (69\%) as seen in Fig. 5. Similar prevalence within the hepatic diseases was represented by viral hepatitis type $A(19 \%)$ and type $B$
(18\%)asseeninFig.6.Among the mostfrequentallergies to drugs were the allergy to antibiotics (41\%) followed by the allergy to anesthetic drugs (18\%) as seen in Fig. 7. Diabetes mellitus type 2 was the most frequent (63\%) according to the average age of the study group as shown in Fig. 8. The most frequent endocrine disorders were represented by hypothyroidism (30\%) followed very closely by hyperthyroidism (29\%) as shown in Fig. 9. Hypoacusis (38\%) was the most common ORL illness, but $19 \%$ of the patients from the study group suffered from ORL infectious diseases like chronic otitis, 


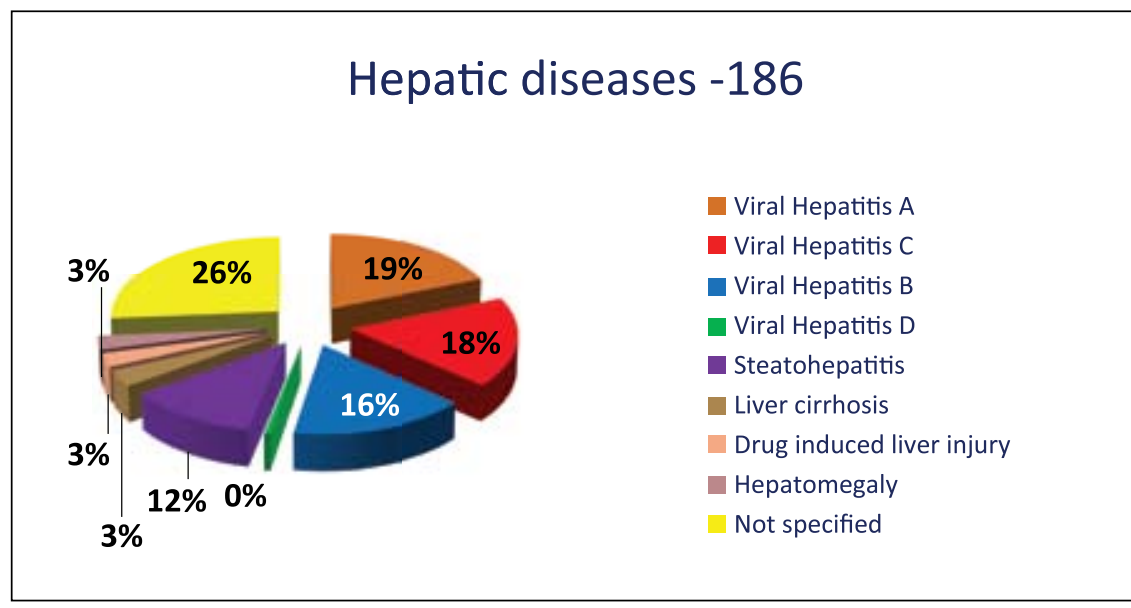

Figure 6.

Hepatic diseases
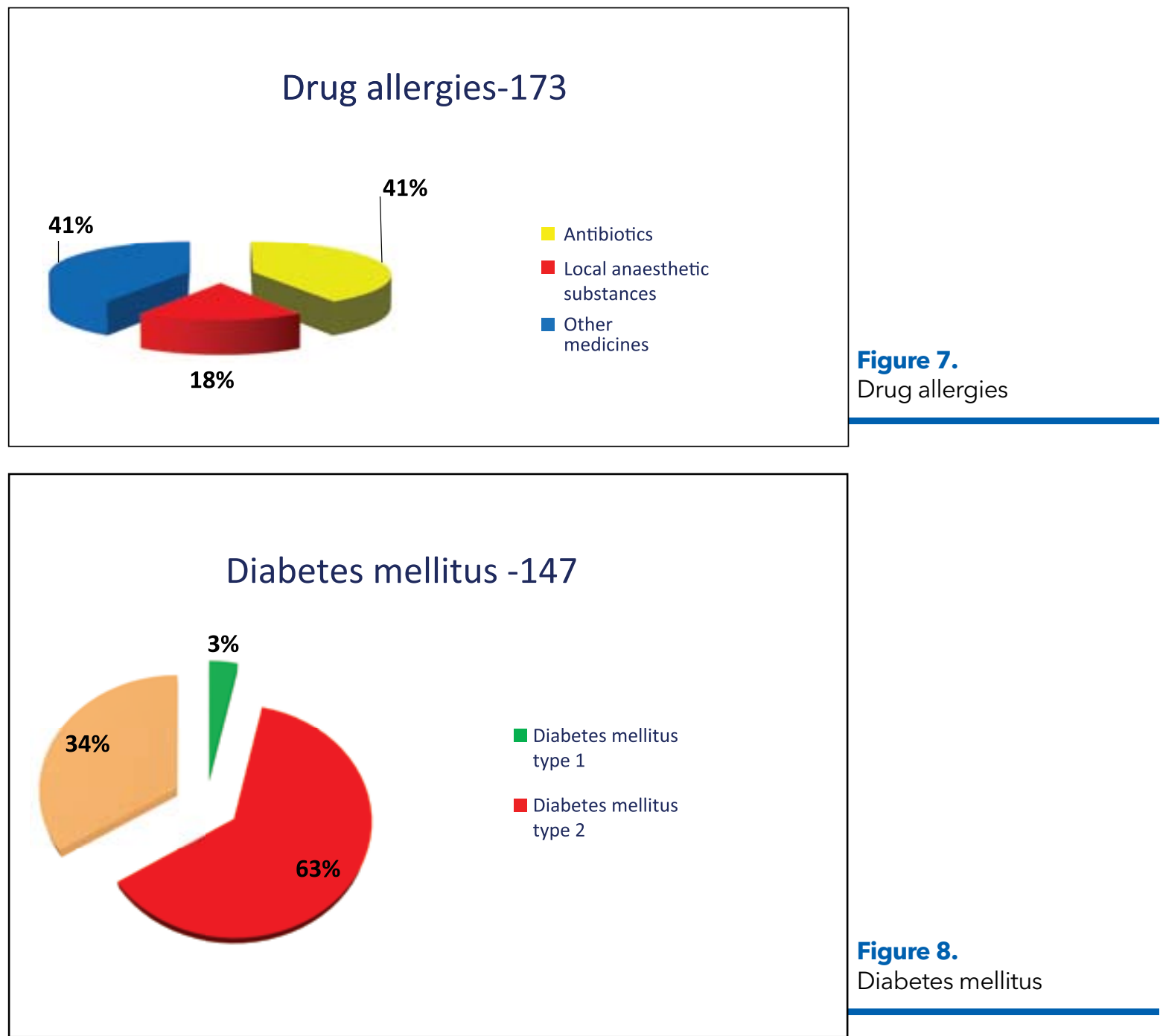

Figure 8.

Diabetes mellitus

chronic rhinitis or nasal sinusitis, as can be seen in Fig. 10. Nephrolithiasis (47\%) was the most frequent kidney disorder. $5 \%$ of the patients had chronic kidney failure as shown in Fig.11.

Among respiratory disorders, the most frequent was asthma (63\%), and $37 \%$ of the patients reported pulmonary tuberculosis in their medical history (Fig. 12). Among the neurologic disorders the most frequent was epilepsy (72\%), and $20 \%$ of the patients had stroke in their medical history as can be seen in Fig. 13.

From the 1176 patients, a percentage of $84 \%$ were under constant medication for their actual disorders as seen in Fig. 14. Almost half of the drugs were represented by B-blockers and diuretics as shown in Fig.15.

\section{Discussion}

From the 1176 patients, most of them were female. This shows a better compliance of women to dental treatments and a higher interest for oral health. Most of the patients were between 56 and 65 years old. The high actual prevalence of comorbidities was $92 \%$ 


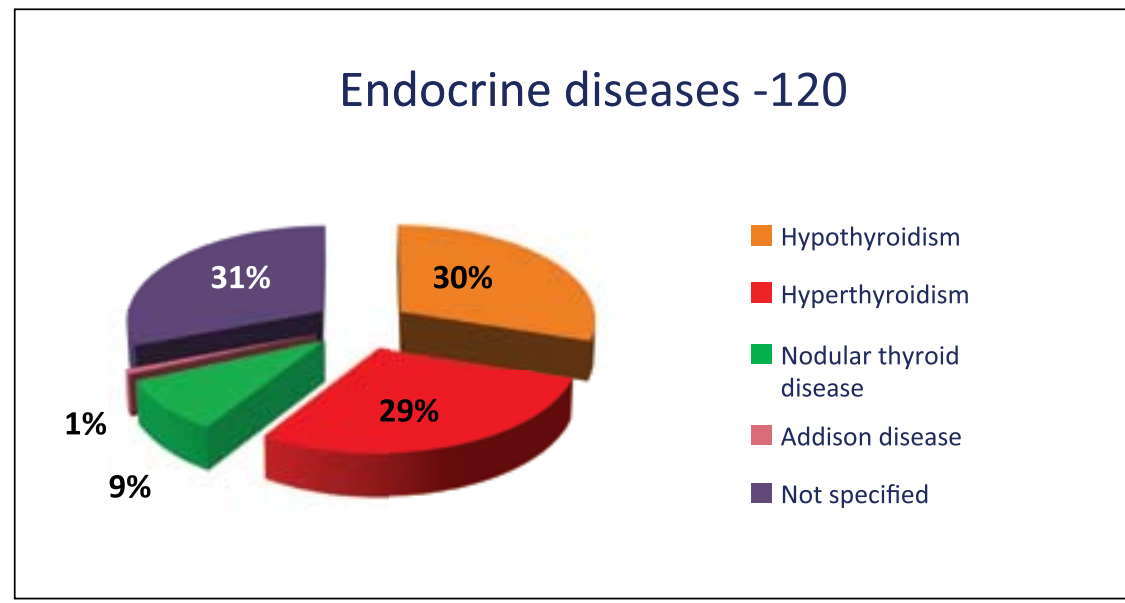

Figure 9.

Endocrine diseases
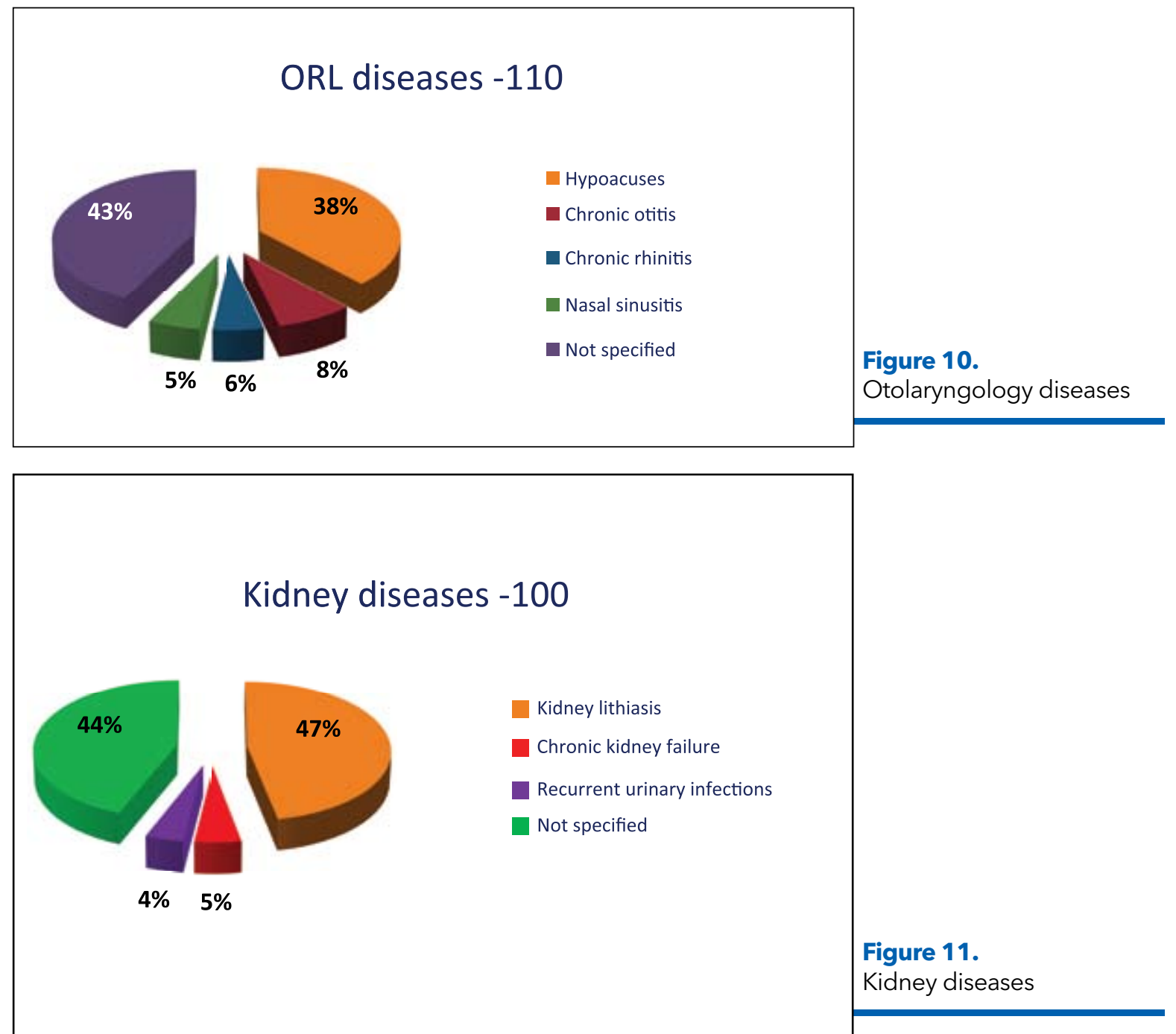

because the majority of the subjects were elders.

The total of the associated diseases was 1593, exceeding the number of patients in the study group, which shows that certain patients had one or more associated comorbidities.

The specific prevalence of different disorders showed that among heart diseases, HBP presented the highest prevalence $(24.84 \%)$ in comparison with coronary heart disease $(3.96 \%)$ or with chronic cardiac failure $(2.16 \%)$. HBP prevalence in Latin America, India and China is between $52.6 \%$ and 79.8
$\%$ in an urban environment and between $42.6 \%$ and $56.9 \%$ in a rural environment (4). The prevalence of cardiac failure in Eastern areas of Africa was $41 \%$, and coronary heart disease has a prevalence of $69 \%$ in Latin America and of $75 \%$ in North Africa (5). Our results are lower than those founde in the mentioned studies, probably due to the smaller size of our sample.

The prevalence of hepatic disorders was $12 \%$ from which $2.16 \%$ were infections with viral hepatitis $\mathrm{C}(\mathrm{VHC})$ and $1.92 \%$ with viral hepatitis $B$ (VHB). 


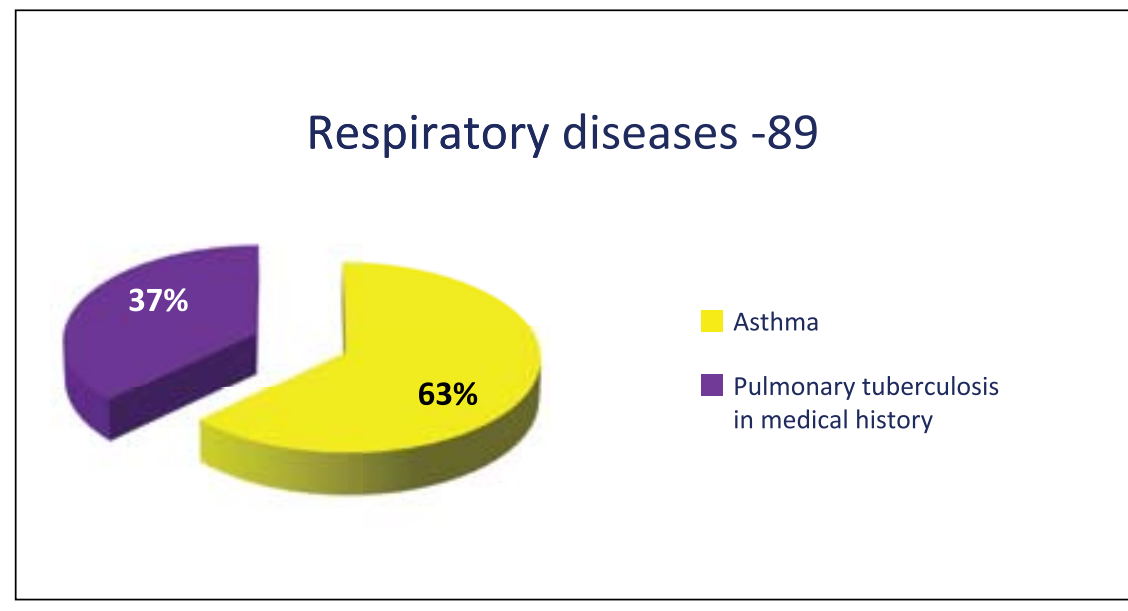

Figure 12.

Respiratory diseases

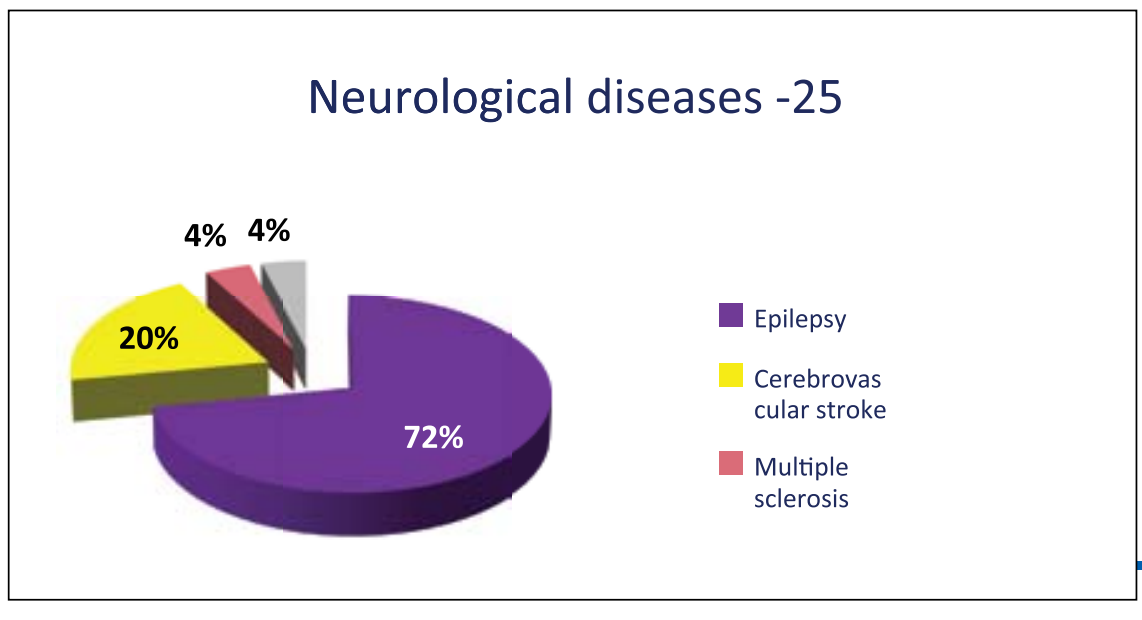

Figure 13.

Neurological diseases

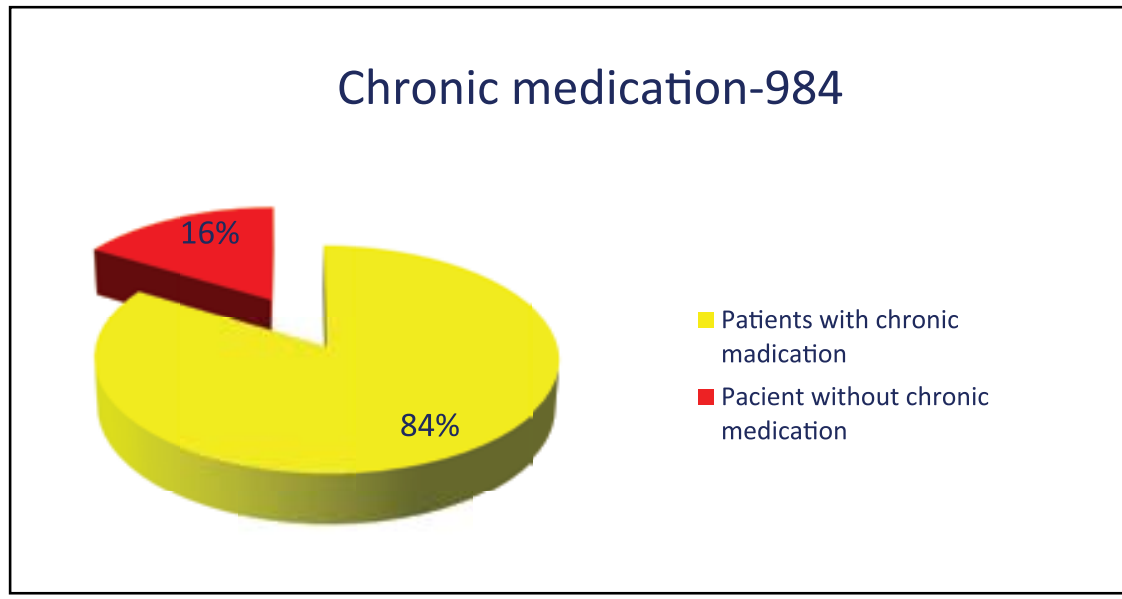

Figure 14.

Permanent medication

Our study shows values lower than those of the Chinese researchers. The prevalence of infection with VHB in China is $~ 10 \%$ at the general population level and $3.2 \%$ for $\mathrm{VHC}(6)$.

The prevalence of Diabetes Mellitus was $9 \%$. The prevalence of diabetes mellitus in New Zeeland is of $20.9 \%$ and the study was conducted on 53911 adult patients (7).

The prevalence of respiratory disorders was $6 \%$ from which $3.78 \%$ were represented by asthma. The prevalence of asthma among the Italian population in 2010 was $6.6 \%$ (8).

The prevalence of neurologic disorders was $2 \%$ of which $1.44 \%$ was represented by epilepsy. The values obtained are almost two times higher as the valued reported among the Turkish population. The prevalence of epilepsy in Turkey was reported between 0.08/1000 inhabitants to 8.5/1000 inhabitants, in the Arabian countries it was of $0.9 / 1000$, and in Sudan, 6.5/1000 inhabitants (9).

The discrepancies when comparing our data with the scientific literature may be due to the following factors: -the size of the study sample which was much smaller (even 53 times smaller than some studies);

-not all the patients presented medical certificates to attest the associated disorders;

-the patient's omission to declare certain associated conditions (either intentionally or not);

-the limited experience of the students and resident doctors in collecting the data. From the 1176 patients, 


\title{
Chronic medication of heart diseases-673
}

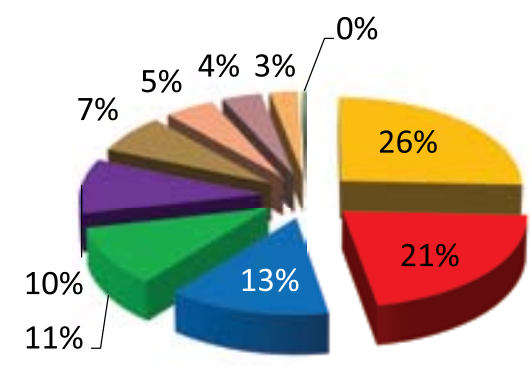

\author{
Beta antagonists \\ - Diuretics \\ - Converting enzyme \\ inhibitors \\ - Vasodilator drugs \\ - Platelet antiaggregants \\ - Calcium channel \\ antagonist receptors \\ Angiotensin receptor \\ inhibitors \\ - Vein tonics \\ Anticoagulant agents \\ - Cardiotonic agents
}

Figure 15.

Permanent medication

for heart disorders
84\% were under constant medication, which represents an additional risk for these patients in the dental office due to the adverse events of these drugs and due to the interference with dental treatments. The medication with B-blockers, diuretics and converting enzyme inhibitors accounted for $60 \%$. Chronic anticoagulant therapy requires specific training of the patient in collaboration with the attending doctor.

\section{Conclusion}

1. The prevalence of comorbidities was high (92\%) among patients from the SANODENTAPRIM program.

2. The specific prevalence of the disorders was smaller than the data from the scientific literature due to the size of the study group and to the way the data was collected.

\section{Bibliography}

1. BlaizotA, Vergnes JN, Nuwwareh S, Amar J, Sixou M. Periodontal diseases and cardiovascular events: metaanalysis of observational studies. Int Dent J. 2009; 59(4):197-209.

2. Ridker PM, Paynter NP, Rifai N, Gaziano JM, Cook NR. C-reactive protein and parental history improve global cardiovascular risk prediction: The Reynolds Risk Score for men. Circulation. 2008; $118(22): 2243-2251$

3. Holmlund A, Holm G, Lind L. Number of teeth as a predictor of cardiovascular mortality in a cohort of 7,674 subjects followed for 12 years. J Periodontol. 2010; 81(6):870-876.

4. Prince MJ, Ebrahim S,Acosta D, Ferri CP, Guerra M, Huang Y, Jacob KS, Jimenez-Velazquez IZ, Rodriguez JL, Salas A, Sosa AL, Williams JD, Gonzalez-Viruet M, Jotheeswaran AT, Liu Z. Hypertension prevalence, awareness, treatment and control among older people in Latin America, India and China: a 10/66 cross-sectional population-based survey. J Hypertens. 2012; 30(1):177-187.

5. Magaña-Serrano JA, Almahmeed W, Gomez E, Al-Shamiri M, Adgar D, Sosner P, Herpin D, I PREFER Investigators. Prevalence of heart failure with preserved ejection fraction in Latin American, Middle Eastern, and North African Regions in the I PREFER study
3. The adverse events of the chronic medication need a special attention especially if certain classes of drugs interfere with dental treatments.

4. The risks of the patient with general disorders have to be evaluated after a detailed patient history corroborated with paraclinical examinations and, if needed, with the cooperation of the attending doctor.

5. The risks of the patient with comorbidities in the dental office are determined by functional, metabolic and hemodynamic imbalances.

6. The need of specific training of the patient with comorbidities in order to correctly follow an anticoagulant treatment for the removal of dental foci or for performing other treatments.

(Identification of Patients With Heart Failure and PREserved Systolic Function: an epidemiological regional study). Am J Cardiol. 2011;108(9):1289-1296.

6. Tanaka M, Katayama F, Kato H, Tanaka H, Wang J, Qiao YL, Inoue M. Hepatitis $B$ and $C$ virus infection and hepatocellular carcinoma in China: a review of epidemiology and control measures. J Epidemiol. 2011; 21(6):401-416.

7. Thornley S, Marshall R, Jackson G, Smith J, Chan WC, Wright C, Gentles D, Jackson R. Estimating diabetes prevalence in South Auckland: how accurate is a method that combines lists of linked health datasets? N Z Med J. 2010; 123(1327):76-86.

8. de Marco R, Cappa V, AccordiniS, Rava M,Antonicelli L, Bortolami 0 , Braggion M, Bugiani M, Casali L, Cazzoletti L, Cerveri I, Fois AG, Girardi P, Locatelli F,Marcon A, Marinoni A, Panico MG, Pirina P, Villani S, Zanolin ME, Verlato G, GEIRD Study Group. Trends in the prevalence of asthma and allergic rhinitis in Italy between 1991 and 2010. Eur Respir J. 2012; 39(4):883-892.

9. Angalakuditi M, Angalakuditi N. A comprehensive review of the literature on epilepsy in selected countries in emerging markets. Neuropsychiatr Dis Treat. 2011; 7:585-597. 


\section{Aranka Ilea}

"Iuliu Hațieganu" University of Medicine and Pharmacy, Department of Oral Rehabilitation, Oral Health and Dental Office Management, Faculty of Dentistry, Cluj-Napoca, România

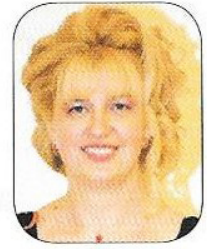

Dr. Aranka llea is an Assistant Professor of Oral Rehabilitation, Oral Health and Management of Dental Office Department at the Faculty of Dentistry

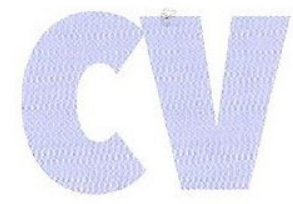
of the "Iuliu Hațieganu" University of Medicine and Pharmacy, Cluj-Napoca, since 2008. She graduated the Faculty of Medicine in 1996 and Faculty of Dentistry in 2000. She is a specialist in dento-alveolar surgery and pediatric neurology. Dr. Aranka llea participated at national and international conferences as a speaker or as a lecturer with over 50 scientific papers. She is an author of 8 articles which were published in Romanian and international journals. Her academic activity was crowned by her election by students as the "Dean of the soul" in 2013. Her main area of interest is the correlation between general conditions and oro-maxillo-facial pathology. Also, she conducted researches in facial nerve pathology and traumatology.

\section{$0.170 \mathrm{stone}$}

What was the prevalence of comorbities in the studied cohort?
- $100 \%$
$92 \%$
- $75 \%$
口 $44 \%$

\section{What were the most frequently associated commorbidities?}
$\square$ Respiratory
$\square$ Cardiovascular
a Gastrointestinal
- Metabolical

\section{What was the most frequent drug allergy?}

- Antibiotics

- Local anaethetics

- Warfarin

$\square$ Other drugs

\section{What determines the risk of the patients with comorbidities in the dental office?}

- Functional imbalances

- Metabolic imbalances

- Hemodynamic imbalances

All of the above 